\title{
Dampak Pengendalian Hama Terpadu Kakao terhadap Serangan Penggerek Buah Kakao (Conopomorpha cramella (Sn.)) (Lepidoptera : Gracillariidae) dan Helopeltis sp. (Hemiptera : Miridae) MUJIONO TARJOKO, DAN SAMUJI
}

Jurusan HPT Fakultas Pertanian Universitas Jenderal Soedirman Kampus Karang Wangkal, Purwokerto

(diterima Oktober 2004, disetuju .April 2005)

\begin{abstract}
Impact of integrated Pest management (IPM) for cacao pod borer attack (Conopomorpha cramella (Sn.)) (Lepidoptera: Gracillaridae) and Helopeltis sp. (Hemiptera: Miridae). Research on impact of integrated Pest management (IPXI) for cacao pod borer atrack (Conopomorpha cramella (Sn.)) and Helopeltis sp. had been conducted at Tumbik Melayu Village, Teluk bayur District, Berau Regency, in East Kalimatan, starting from May to September 2002. It used nested classification design. IPXI practices applied in this research were pruning, balanced fertilization, wecding, field sanitation (leaf mulch), light pruning, fregment harvesting (every week), burrying of pod shell, and wrapping of young pod in week $15^{\text {th }}$. Result of the resarch revealed that IPM application could reduce the cacao pod borer attack reaching: a) light category beforc treatments from 41.29 to $15.00^{\circ} \%$; b) heavy caregory before treatments from 20.56 to 0 and $23.37 \%$, compare to farmer plot. IPM implementation were able to increase percentages of healthy pod up to $18.66 \%$ compared to Farmer plot. Besides it could suppres developments of Helopelitis sp. population up to $24 \%$. The dominant natural enemies were spider as many as 1.34 individuals per plant on IPM plot and 0.6 spider per plant on farmer plot (non IPM), Application of IPMf practices were alble to increase agronomic character: a) number of flower up to $37.22 \%$ when compared to farmer plot, and b) number of fruts until $5.56 \%$, whereas number of young fruits decreasc up $13.25 \%$
\end{abstract}

KEY WORDS: Integrated pest management, cacao pod borer, Helopeltis sp.

\section{PENDAHULUAN}

Usaha perkebunan dalam merebut pasar global dihadapkan pada persaingan yang semakin ketat. Konsumen pasar global saat ini adalah konsumen sadar lingkungan (konsumen hijau), sehingga persyaratan ramah lingkungan dalam produksi komoditas perkebunan sudah merupakan persyaratan minimal yang harus dipenuhi olch pihak eksportir (Mujiono dan Sabirin, 2002).

Peluang pasar dunia untuk kakao sebenarnya masih cukup besar, produksi kakao dunia saat ini \pm 3 juta ton per tahun, dan lebih dari $70 \%$ dari produksi dihasilkan oleh riga negara penghasil utama, yaitu Pantai Gading, Ghana dan 
Indonesia. Kontribusi kakao Indonesia dalam produksi dunia hanya $\pm 12 \%$ (Wardani, 2002). Jika kita amati sejak terjadinya krisis ekonomi, komoditas perkebunan termasuk kakao merupakan sumber penghasil devisa yang sangat penting, namun berdasarkan harga ratarata biji kakao, setiap tahun Indonesia menderita kehilangan pendapatan sebesar 50-100 juta dolar AS akibat dikenakan diskon harga sebesar $5-15 \%$ (Wardani, 2002). Hal tersebut karena kualitas biji yang kurang baik akibat kerusakan olch hama dan patogen. Sebaliknya Ghana selama ini diakui sebagai negara produsen kakao dengan kualitas sangat baik mendapatkan premium 15 $20 \%$.

Gangguan serangan hama dan patogen penyebab penyakit masih merupakan faktor pembatas utama dalam usaha meningkatkan produksi dan mutu kakao, diantaranya yang sangat merugikan adalah Penggerek Buah Kakao (PBK) (Conopomorpha cramella (Sn.)), Helopeltis sp. dan busuk buah (Pbytophtbora palmivora Butl.). Cara mengatasi permasalahan tersebut yang paling tepat adalah dengan menerapkan konsep Pengendalian Hama Terpadu (PHT) yang menurut Lntung (2002) lebih bersifat komprehensip dan mencakup aspek teknis, ekologis, ekonomis-bisnis, sosial budaya serta politis. Penerapan PHT sangat sesuai dalam strategi menghadapi persaingan bebas, karena sejalan dengan tuntutan konsumen dunia terhadap produk yang "aman", yaitu yang diproduksi melalui proses yang ramah lingkungan.
Tujuan penelitian ini adalah:

1. Mengetahui dampak penerapan PHT kakao terhadap intensitas serangan PBK dan populasi / Helopeltis sp.

2. Mengetahui perbandingan populasi musuh alami antara petak PHT dan petak petani (PP)

3. Mengetahui aspek dampak penerapan PHT kakao terhadap peningkatan bunga, pentil dan buah.

\section{BAHAN DAN METODE}

Penelitian ini dilaksanakan di dusun Merang, Kampung Tumbit Melayu, Kecamatan Teluk Bayur, Kabupaten Berau, Kalimantan Timur, mulai tanggal 20 Mei sampai 30 September 2002.

Bahan yang digunakan dalam penelitian ini yaitu pupuk Urea, KCL, dan TSP. Selain itu kebun kakao sebagai lokasi petak percobaan seluas $\pm 0,5 \mathrm{Ha}$ dengan umur \pm 7 tahun. Kondisi tanaman kurang terawat, pelindung kurang, keadaan gulma lebat/Kompak.

Alat yang digunakan adalah cangkul, garpu tanah, egrek, gunting pangkas, gergaji, alat pemanen, plastik, dll.

Penelitian ini dilaksanakan menggunakan eksperimen dengan rancangan pola tersarang. Sebagai kelompok (group) adalah petak $\mathrm{PHT}$ dan petak petani (PP) dengan luas masing-masing $0,3 \mathrm{Ha}$ ( \pm 400 tanaman) dengan jarak diantaranya $50 \mathrm{~m}$. Setiap kelompok dibagi menjadi 3 petak sebagai ulangan, masingmasing terdiri 100 tanaman. Jumlah pohon sampel per ulangan 10 tanaman. 
Perlakuan PHT yang diterapkan tersaji pada Tabel 1.

Parameter yang diamati adalah: a) tingkat serangan $\mathrm{PBK}, \mathrm{b}$ ) populasi Helopeltis sp., c) perkembangan musuh alami (predator), d) parameter agronomi terdiri dari bunga, pentil, dan buah. Kriteria tingkat serangan PBK ringan, yaitu biji berwarna hitam tetapi tidak lengket, sedangkan kategori berat, biji berwarna hitam dan lengket.

Pengamatan dilakukan selama 20 minggu. Untuk parameter agronomi sample tanaman tetap, sedangkan untuk parameter hama tidak tetap dengan teknik zig zag, diagonal, bujur sangkar memanjang, dan bujur sangkar melebar secara bergantian setiap minggu. Hal ini dilakukan agar data lebih representatif karena sebaran hama cenderung berubah-ubah. Pengamatan intensitas serangan hama dilakukan bersamaan waktu panen.

\section{HASIL DAN PEMBAHASAN}

\section{Tingkat Serangan PBK}

\section{Kategori Serangan Ringan (Biji ber- warna hitam tetapi tidak lengket)}

Tingkat serangan PBK kategori ringan untuk petak $\mathrm{PHT}$, tertinggi pada minggu ke-4 $(50 \%)$ dan terendah pada minggu ke-20 (15\%) dengan rata-rata $31,70 \%$, sedangkan pada PP tingkat serangan itu tertinggi pada minggu ke-16 $(38,38 \%)$ dan terendah pada minggu ke$2(22,48 \%)$ dengan rata-rata $46,17 \%$, dan tidak berbeda nyata antar $\mathrm{PP}$ dan $\mathrm{PHT}$ (Tabel 2 dan 3). Jika dilihat dari data awal dan akhir (sebelum dan sesudah perlakuan), maka petak PHT dapat mengurangi tingkat serangan $\mathrm{PBK}$ dari $41,29 \%$ menjadi $15 \%$ atau turun sebesar $26,29 \%$, sedangkan pada PP ada penambahan tingkat serangan sebesar $5,74^{\circ} \%$ yaitu $22,48 \%$ menjadi $27,95 \%$ (Gambar 1 dan Tabel 4).

Tabel 1. Uraian perlakuan yang diterapkan dalam penelitian.

\begin{tabular}{ccc}
\hline \hline No. Uraian Perlakuan & Petak PHT & Petak petani (PP) \\
\hline 1. Pemangkasan & Ya & Tidak \\
2. Pemupukan berimbang & Ya & Tidak \\
3. Penyiangan gulma & Ya & Tidak \\
4. Sanitasi kebun (seresah daun) & Ya & Tidak \\
5. Wiwilan & Ya & Tidak \\
6. Pemanenan & 1 minggu sekali & 2 minggu sekali \\
7. Penguburan kulit buah & Ya & Tidak \\
8. Pembungkusan buah muda kakao & Ya & Tidak \\
\hline
\end{tabular}

Tabel 2. Futarata pepulas Helopetts sp tngkkat serangan PgK, musuh alani, dan parametor agronom pada polak Petani

\begin{tabular}{|c|c|c|c|c|c|c|c|c|c|c|c|c|c|c|c|c|c|c|c|c|c|c|}
\hline \multirow{2}{*}{  } & \multicolumn{20}{|c|}{  } & \multirow{2}{*}{ 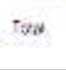 } & \multirow{2}{*}{$\begin{array}{l}\text { Ros. } \\
\text { rots }\end{array}$} \\
\hline & 1 & it & in & is & $v$ & B & vii & in & $x$ & $x$ & $x$ & xi & xili & $x N$ & $x v$ & $x_{0}$ & $x$ : & 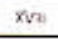 & $\mathrm{nx}$ & $x x$ & & \\
\hline 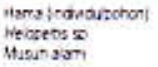 & 063 & 1,10 & 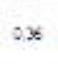 & 0.9 & 9,6 & 0.2 & 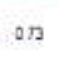 & 006 & 0.45 & 004 & 604 & 0.00 & 000 & 210 & 023 & 0,0 & 0.00 & $\Delta 0 ;$ & 0,0 & 6,0 & 6.93 & 0.35 \\
\hline $\begin{array}{l}\text { seruigranang } \\
\text { eminiagers }\end{array}$ & $0 \leqslant 5$ & 10 & $2 \pi$ & 19 & 273 & $00^{\circ}$ & 122 & 13 & 150 & 113 & 103 & 43 & 100 & 120 &, 70 & 18 & 177 & $\infty$ & 176 & $\Delta, 008$ & $\begin{array}{l}0 x \mathrm{se} \\
0.05 \\
25 \div 4\end{array}$ & $\begin{array}{l}0.00 \% 4 \\
2003 \\
114\end{array}$ \\
\hline $4 \% 50$ & & & & & & & & & & & & & & & & & & & 110 & 76. & & \\
\hline 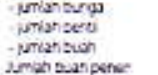 & 321 & $1.7 \%$ & $\begin{array}{l}24.63 \\
1.53\end{array}$ & $\frac{3436}{203}$ & $\begin{array}{l}24 \\
4\end{array}$ & 6,73 & $\begin{array}{l}41.56 \\
902\end{array}$ & $\frac{3,00}{320}$ & 3710 & 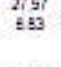 & 8,17 & 127 & 550 & $\frac{30}{607}$ & $T 13$ & 43 & $\begin{array}{l}\text { No } \\
687\end{array}$ & 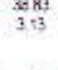 & 4.56 & 3,97 & ress & 5,03 \\
\hline $\begin{array}{l}2 \text { mots } \\
\text { inniar } \\
\text { ture } \\
\text { tincter }\end{array}$ & $\begin{array}{l}20 \leq t \\
3916\end{array}$ & $\begin{array}{l}1000 \\
5 \pi\end{array}$ & $\begin{array}{l}15 E ! \\
4 E 5\end{array}$ & $\begin{array}{l}100 \\
n \div 6\end{array}$ & $\begin{array}{l}1923 \\
2400\end{array}$ & $\begin{array}{l}1467 \\
18 \& 5\end{array}$ & $\begin{array}{l}1633 \\
n 04\end{array}$ & $\begin{array}{l}13: 00 \\
31,48\end{array}$ & $\begin{array}{l}23,33 \\
27,15\end{array}$ & $\begin{array}{l}1433 \\
38,05\end{array}$ & $\begin{array}{l}900 \\
2728\end{array}$ & $\begin{array}{l}4.13 \\
\text { \&.E }\end{array}$ & $\begin{array}{l}100 \\
3926\end{array}$ & $\begin{array}{l}200 \\
5000\end{array}$ & $\begin{array}{r}500 \\
5543\end{array}$ & $\begin{array}{l}60 \\
5 x\end{array}$ & $\begin{array}{l}1167 \\
6902\end{array}$ & $\begin{array}{l}100 \\
6900\end{array}$ & $\begin{array}{l}x, 00 \\
8100\end{array}$ & $\begin{array}{l}20,93 \\
\cos 00\end{array}$ & $\begin{array}{l}285.30 \\
923,4\end{array}$ & $\prod_{2017}^{1327}$ \\
\hline 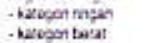 & $\begin{array}{l}41.29 \\
7058\end{array}$ & $\begin{array}{l}27.99 \\
1534\end{array}$ & 2575 & $\frac{500}{7725}$ & $\begin{array}{l}198 \\
5011\end{array}$ & is 3 A & 40 & $\frac{36}{19} 39$ & $\begin{array}{ll}31,16 \\
41,70\end{array}$ & $\begin{array}{l}15,35 \\
51,55\end{array}$ & $\begin{array}{l}3194 \\
4328\end{array}$ & $\begin{array}{l}3: 94 \\
: 9 * 4\end{array}$ & $\begin{array}{l}2015 \\
21.59\end{array}$ & 5000 & $\begin{array}{l}2323 \\
839\end{array}$ & $\begin{array}{l}300 \\
13 y\end{array}$ & 32,42 & $x>0$ & $x_{100}$ & 1502 & $\begin{array}{ll}51425 \\
4058\end{array}$ & $\begin{array}{l}39 \pi \\
2239\end{array}$ \\
\hline
\end{tabular}


Kategori Serangan Berat (Biji berwarna hitam dan lengket)

Tingkat serangan PBK kategori berat pada petak PHT, tertinggi pada minggu ke-5 $(56,11 \%)$ dan terendah pada minggu ke-14, 17, 18, dan 20 sebesar $0 \%$ dengan rata-rata $22,39 \%$. Pada petak $\mathrm{PP}$, tingkat serangan itu tertinggi terjadi pada minggu ke- $14(38,46 \%)$ dan terendah pada minggu ke-20 (20,33\%) dengan rata-rata $28,88 \%$ (Tabel 2 dan 3 ). Petak PHT jika dibandingkan dengan PP menunjukkan perlakuan PHT dapat menekan tingkat serangan PBK (kategori berat) sebesar $22,37 \%$ dan berbeda nyata antar petak PHT dan PP (Gambar 2 dan Tabel 4).
Jika diperhatikan tingkat serangan awal dan akhir (sebelum dan sesudah perlakuan) dari $20,56 \%$ menjadi $0 \%$ atau dapat menekan sebesar $100 \%$, sedangkan pada petak PP hanya sebesar $41,86 \%$ (Tabel 4). Hal ini disebabkan olch penerapan PHT kakao terutama komponen pemangkasan, penguburan kulit buah, sanitasi kebun, panen sering dan pembungkusan buah muda yang berdampak positif terhadap penurunan tingkat serangan $\mathrm{PBK}$. Menurut Mumford (1986) dan Mumford and Ho (1988) pengendalian PBK dengan pemangkasan, panen sering, dan pembungkusan buah muda (panjang buah kurang dari $7 \mathrm{~cm}$ ) dapat mengurangi populasi $C$.

Tabel 3. Rata-rata populasi Helopeltis sp., tingkat serangan PBK dan parameter agronomi selama 20 kali pengamatan.

\begin{tabular}{|c|c|c|c|c|c|c|c|}
\hline \multirow{2}{*}{ Perlakuan } & \multirow{2}{*}{$\begin{array}{c}\text { Populasi } \\
\text { Helopeltis sp. }\end{array}$} & \multicolumn{2}{|c|}{ Tingkat serangan PBK } & \multicolumn{4}{|c|}{ Parameter agronomi } \\
\hline & & $\begin{array}{l}\text { Kategori } \\
\text { Ringan }\end{array}$ & $\begin{array}{c}\text { Kategori } \\
\text { Berat }\end{array}$ & $\begin{array}{c}\text { buah sehat } \\
\text { (\%) }\end{array}$ & $\begin{array}{l}\text { Jumlah } \\
\text { bunga }\end{array}$ & $\begin{array}{l}\text { Jumlah } \\
\text { pentil }\end{array}$ & $\begin{array}{l}\text { Jumiah } \\
\text { Buah }\end{array}$ \\
\hline PHT & $0,38 \mathrm{a}$ & $31,73 a$ & $22,42 a$ & $45,85 a$ & $35,69 a$ & $5,43 a$ & $6,06 a$ \\
\hline Petani/PP & $0,50 a$ & $32,48 a$ & $28,88 b$ & $38,64 b$ & $26,89 b$ & $6.26 a$ & $5,74 a$ \\
\hline$\%$ terhadap PP & 24,00 & - & 22,37 & 18,66 & 32,73 & - & 5,57 \\
\hline
\end{tabular}

Tabel 4. Populasi Helopeitis sp., tingkat serangan PBK dan persentase buah sehat pada awal dan akhir pengamatan.

\begin{tabular}{lrrrrrrrrr}
\hline \hline \multirow{2}{*}{ Parameter } & \multicolumn{4}{c}{ PHT } & \multicolumn{3}{c}{ PP } \\
\cline { 2 - 9 } & Awal & Akhir & Delta & \% terhadap awal & Awal & Akhir & Deita $\%$ terhadap awal \\
\hline Tk. Serangan PBK: & & & & & & & & & \\
Ringan & 41,29 & 15,00 & 26,29 & 63,67 & 22,48 & 27,95 & $-5,47$ & $-24,33$ \\
Berat & 20,56 & 0,00 & 20,56 & 100,00 & 34,97 & 20,33 & 14,64 & 41,86 \\
Populasi Helopeltis sp. & 0,83 & 0,10 & 0,73 & 87,95 & 0,43 & 0,97 & $-0,54$ & $-125,58$ \\
Persentase buah sehat & 38,16 & 85,00 & $-46,84$ & $-122,75$ & 42,55 & 51,71 & $-9,16$ & $-21,53$ \\
\hline
\end{tabular}

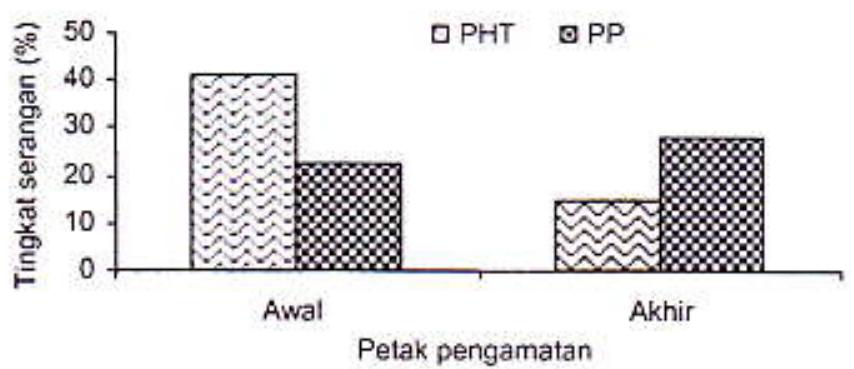

Gambar 1. Rata-rata tingkat serangan PBK kategori ringan. 


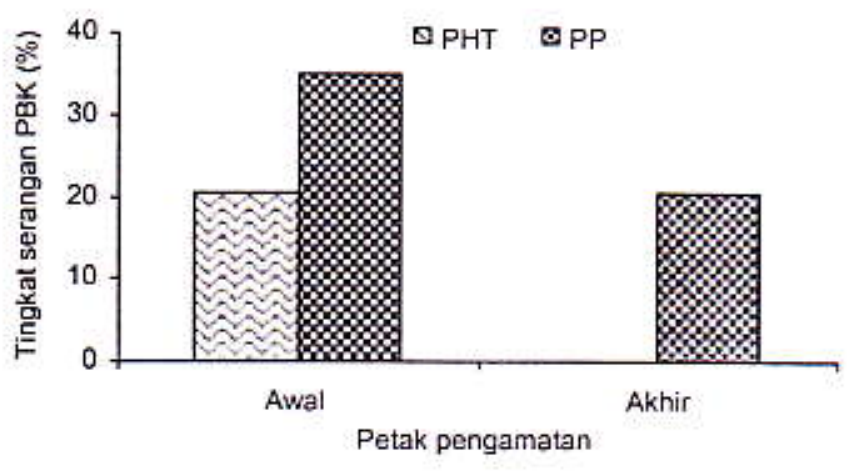

Gambar 2. Tingkat serangan PBK kategori berat.

cramella. Hal itu terjadi karena pemangkasan akan menciptakan kondisi kebun yang tidak cocok untuk perkembangan populasi $\mathrm{PBK}$, sedangkan panen sering akan membantu terputusnya siklus hidup hama serta buah muda yang dibungkus akan terlindungi olch serangan C. cramella. Kebersihan pada penelitian ini lebih tinggi dari penerapan PHT

Kakao di Kabupaten Simalungun, Sumut (dari $25 \%$ menjadi $10 \%$ ) tetapi lebih rendah dari Kabupaten Asahan (dari $70 \%$ menjadi 20\%) (BAGPRO PHT-PR Sumut, 2002). Hasil penelitian Puslit Kopi dan Kakao (1999) menunjukkan bahwa penerapan PHT di perkebunan kakao rakyat Kabupaten Asahan dapat mengurangi intensitas serangan PBK dari $83,3 \%$ menjadi $23 \%$ setelah 2 minggu perlakuan, dan penekanan tingkat serangan di bawah ambang ekonomi ( 2 individu per tanaman), dicapai dalam waktu 12 minggu setelah awal perlakuan.

\section{Persentase Buah Sehat}

Persentase buah panen sehat (bebas dari gejala serangan PBK) pada petak PHT, tertinggi pada minggu ke-20 $(85 \%)$ dan terendah pada minggu ke-6 $(18,46 \%)$ dengan rata-rata $45,85 \%$, sedangkan pada petak PP, tertinggi pada minggu ke-18 $(53,49 \%)$ dan terendah pada minggu ke-12 (23,15\%) dengan rata-rata $38,64 \%$ dan berbeda nyata antar petak PHT dan PP (Tabel 5 dan 2). $\mathrm{Hal}$ ini menunjukkan bahwa perlakukan PHT meningkatkan buah sehat sebesar $18,66 \%$. Jika dilihat dari data awal dan akhir (sebelum dan sesudah perlakuan), maka pada petak $\mathrm{PHT}^{\top}$ ada peningkatan buah panen sehat sebesar $414,85 \%$ (Tabel 4 dan Gambar 3). Hal ini disebabkan setelah dilakukan penerapan PHT ada penurunan serangan PBK (kategori berat) dari $20,56 \%$ menjadi $0 \%$ dan berpengaruh positif terhadap persentase peningkatan persentase buah sehat. Persentase buah sehat pada PP hanya mengalami kenaikan sebesar $9,16 \%$.

\section{Helopeltis sp.}

Hasil pengamatan terhadap populasi Helopeltis sp. menunjukkan bahwa pada petak PHT, populasi tertinggi terjadi pada pengamatan minggu ke-5 $(1,16$ 
individu per pohon) dan terendah pada pengamatan minggu ke-12 dan ke-13 sebesar 0 , dengan tata-rata sampai minggu ke-20 sebesar $0,38 \%$ individu per pohon (Tabel 5 dan 2). Pada petak PP, populasi tertinggi pada pengamatan minggu ke-3 dan ke-5 (1,2 individu per pohon) dan terendah pada pengamatan minggu ke-14 (0,13 individu per pohon) dengan rata-rata sebesar 0,5 individu per pohon. lika dibandingan dengan petak PP, maka perlakuaan $\mathrm{PH}^{\prime} \mathrm{I}^{\circ}$ dapat menekan populasi Helopeltis sp. sebesar $24 \%$ (Tabel 3 dan Gambar 4). Hal ini karena pada petak $\mathrm{PHI}$ ada perlakuan pemangkasan dan sanitasi kebun yang menyebabkan lebih banyak sinar matahari yang masuk ke kebun, sehingga menghambat perkembangan Helopelfts sp. Selain itu juga discbabkan pada petak PHT populasi alami berupa laba-laba predator (famili
Salticidae dan Araneac) lebih tinggi pada petak PHT dari pada PP (Tabel 5 dan 2). Menurut hasil penelitian Widiasih (2004) pada perlakuan satu individu taba-laba salticidac dengan lima individu Helope/li, sp. Laba-laba tersebut mampu memangsa sampai $66,67 \%$ setelah 24 jam setelah laba-laba dimasukkan.

\section{Musuh Alami}

Semut Angkrang (Oecopbylla smaragdina (F.))

Selama pengamatan sampai minggu ke-20 keberadaan semut angkrang pada petak PHT ditemukan dalam populasi kecil sekali, yaitu pada minggu ke- 8 hanya sebesar $(0,06$ individu per tanaman) dengan rata-rata 0,003 individu pertanaman, sedangkan di $p p$ tidak ditemukan (Tabel 5 dan 2).

Tabel 5. Aatarata popuizs Hebpehs sp, tngkat serargan PBK, musuh alam, dan parameser agronomi pada petsk. PHT

\begin{tabular}{|c|c|c|c|c|c|c|c|c|c|c|c|c|c|c|c|c|c|c|c|c|c|c|}
\hline \multirow{2}{*}{ Uesen } & \multicolumn{20}{|c|}{ 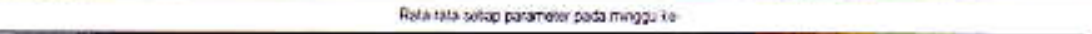 } & \multirow{2}{*}{184} & \multirow{2}{*}{ fara } \\
\hline & 1 & 1 & II & in & $v$ & n & bit & sti & ax & $x$ & $x$ & $x \| 1$ & xम & xy & $x$ & $x=$ & $x \mathrm{n}$ & xist & $x i x$ & $x$ & & \\
\hline 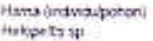 & (64) & 047 & 120 & 059 & 1.20 & 137 & $0 b_{5}$ & 073 & $8: 3$ & 0.25 & 076 & & & & & & & & & & & \\
\hline Mriven n & 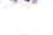 & 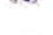 & 政 & 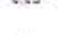 &  & a & Uad & 0,13 & 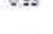 & 0.0 & Wh & 0.16 & W & Q 12 & $0(0)$ & 0.16 & .23 & $e 23$ & $\sqrt{3.3}$ & 3.7 & 39 & 65: \\
\hline sendgerm & & & $=$ &  & : & : & $\therefore$ & $\therefore$ & 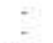 &  & & & & & 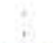 & : & & & & & & \\
\hline  & 0.57 & 2,30 & $0.8 \%$ & $12 \pi$ & 1.20 & 513 & $09 \pi$ & 0.73 & 0.27 & $0 \times \mathbf{\infty}$ & 0,0 & 0.30 & 0.37 & ass & 0.00 & 0.17 & 630 & 0.32 & $o n$ & 0.32 & 12.08 & a.so \\
\hline Imberst & 2043 & 2100 & 2580 & 31,73 & 223 & 330 & 37.23 & 4263 & 30,0 & 21,03 & 15.40 & 2433 & $23 \mathrm{~m}$ & 21,10 & 2450 & 22.70 & $2 \leqslant 5$ & 2257. & 2365 & $290 \%$ & 597 it: & $26 t a$ \\
\hline isme & & 200 & 353 & 4,45 & & & 6.17 & 5 & & & 10,80 & 52,33 & 8,87 & 750 & 440 & $4 E T$ & 4,17 & $d x$ & 83 & 203 & 2 & 626 \\
\hline $\operatorname{liming}_{x \rightarrow \text { into }}$ & 380 & $3 x$ & 223 & 1,87 & 258 & $21 ?$ & 337 & 250 & 43 & 450 & 463 & 6.73 & 5,00 & 7.00 & 8.30 & $17 \mathrm{y}$ & \&.s. & 100 & 1.37 & $1: 5$ & $\$ 50$ & 479 \\
\hline & $=$ & a3. & & 2 & & 260 & & & . & 3 & & $\pi$ & & & . & &  & & & & & 8 \\
\hline $\begin{array}{l}\text { Kianser } \\
\text { ling }\end{array}$ & & 42,55 & - & $\$ 27$ & & 6. & & $36 \times 5$ & & 35,3 & . & 22 is & & 42. & &  & $=$ & 58 & & bin & 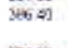 & 1922 \\
\hline & . & 22 & - & & 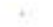 & 32 & & & & $j \pm 0$ & . & 434 & & 12 & & 393 & & & 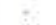 & 6 & & 5224 \\
\hline - $6 x \operatorname{cog} n t$ & $=$ & 34.97 & $\therefore$ & 22 ot & t. & 3i 27 & & 202 &  & $25:$ & . & 3143 & & $3 x, 42$ & & $x_{1}, 4$ & & 7902 & $\therefore$ & 20.8 & 2069 & $22 \mathrm{es}$ \\
\hline
\end{tabular}

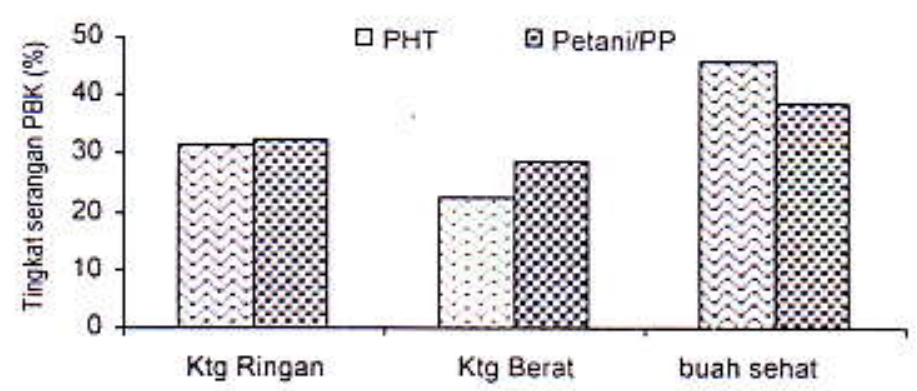

Gambar 3. Rata-rata tingkat serangan PBK selama 20 kali pengamatan 


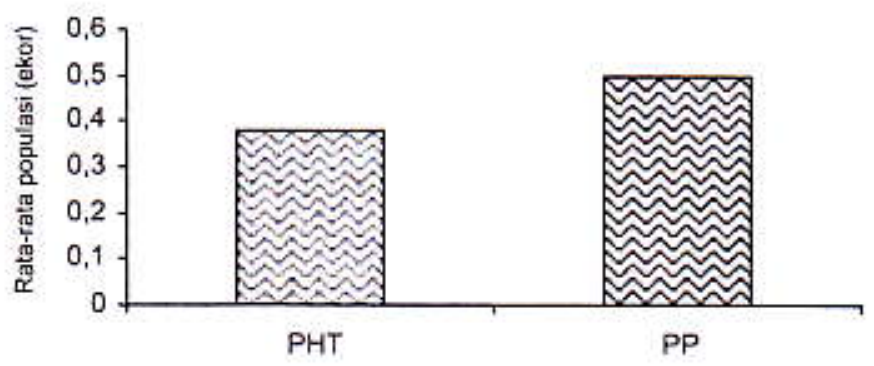

Gambar 4. Rata-rata populasi Helopeltis sp. pada petak PHT dan PP.

\section{Semut Gramang (Anoplepis longipes (Jerdon))}

Hasil pengamatan predator semut gramang pada petak PHT pada pengamatan minggu ke-20 juga ditemukan semut gramang $(0,006$ individu per tanaman), sedangkan di petak PP tidak ditemukan (Tabel 2 dan 3).

\section{Laba-laba}

Hasil pengamatan terhadap labalaba menunjukkan bahwa pada petak PHT, populasi laba-laba teringgi terjadi pada minggu ke-15 (1,96 individu per tanaman) dan terendah pada minggu ke3 (0,7 individu pertanaman) dengan ratarata 1,34 individu pertanaman, sedangkan pada petak PP yang tertinggi terjadi pada minggu ke-4 $(1,27$ individu pertanaman) dan terendah pada minggu ke15 dan ke-17 (0,3 individu pertanaman) dengan rata-rata 0,6 individu per tanaman (Tabel 5 dan 2). Jenis laba-laba yang dominan adalah laba-laba lompat (Araneae : Salticidae) dan Laba-laba serigala (Araneae : lycosidae). Widiasih (2004) melaporkan laba-laba famili Salticidae merupakan laba-laba yang paling dominan ditemukan pada per tanaman kakao di P.T. Rumpun Sari Antan IV, Banyumas.

\section{Agronomi (Bunga, Pentil, dan Buah)}

\section{Jumlah Bunga}

Hasil pengamatan terhadap jumlah bunga menunjukkan bahwa jumlah tertinggi bunga pada petak PHT terjadi pada minggu ke-15 (48) dan terendah pada minggu ke-1 $(20,13)$ dengan rata-rata 35,69 pertanaman, sedangkan pada petak PP tertinggi pada minggu ke-7 $(37,23)$ dan terendah pada minggu ke-2 $(21,07)$ dengan rata-rata 26,89 pertanaman dan berbeda nyata antar PHT dan PP (Tabel 2 dan 3). Perlakuan PHT ternyata meningkatkan persentase jumlah bunga sebesar $27,77 \%$ (Gambar 5).

\section{Jumlah Pentil}

Pengamatan jumlah pentil pada petak PHT menunjukkan bahwa jumlah tertinggi pada minggu ke-10 $(8,83)$ dan terendah pada minggu ke-3 $(1,63)$ dengan rata-rata 5,43 per tanaman, sedangkan pada petak PP tertinggi pada minggu ke-10 dan terendah pada minggu ke- 1 $(1,9)$ dengan rata-rata 6,26 per tanaman (Gambar 5). 




Gambar 5. Parameter agronomi pada perlakuan PHT dan PP.

\section{Jumlah Buah}

Hasil pengamatan terhadap jumlah buah menunjukkan bahwa pada petak PHT, jumlah tertinggi buah terjadi pada minggu ke-19 dan $20(13,37)$ dan terendah pada minggu ke-2 (1,7) dengan ratarata 6,06 buah per tanaman, sedangkan pada petak PP, jumlah tertinggi buah terjadi pada minggu ke-20 $(11,57)$ dan terendah pada minggu ke-4 $(1,67)$ dengan rata-rata 5,74 buah per tanaman dan persentase kenaikannya dibanding. kan PP sebesar $5,57 \%$. Walaupun jumlah pentil pada petak PHI lebih rendah dari PP, namun jumlah buah jadinya lebih banyak. Hal ini karena pada petak $\mathrm{PHT}$ setelah penerapan PHI terutama komponen pemangkasan dan pemupukan dapat meningkatkan jumlah pentil jadi buah atau jumlah chere/l willt lebih sedikit.

\section{KESIMPULAN}

1. Pencrapan PHT berdampak positif terhadap penekanan serangga PBK untuk : a. Karegori ringan dari awal $41,29 \%$ menjadi $15 \%$.

b. Kategori berat dari awal $20,56 \%$ menjadi $0 \%$ dan sebesar $22,37 \%$.

2. Penerapan PHT berdampak meningkatkan persentase buah sehat (bebas serangan $\mathrm{PBK}$ ) sebesar $18,66 \%$ dibandingkan petak petani.

3. Penerapan PHT berdampak positif menekan perkembangan populasi hama Helopeltis sp.

4. Musuh alami yang paling dominan adalah predator laba-laba dengan rata-rata 1,34 individu per tanaman pada petak PHT dan 0,6 individu per tanaman pada petak petani.

5. Penerapan PHT berdampak positif meningkatkan perkembangan parameter agronomi :

a. Jumlah bunga scbesar $32,73 \%$ dibandingkan petak petani.

b. Jumlah buah sebesar $5,57 \%$ dan jumlah pentil mengalami penurunan sebesar $13,25 \%$. 


\section{DAFTAR PUSTAKA}

B.IGPRO PHIT-PR SUMUT. 2002. Pelaksanaan SL-PHT dan Implementasi PHT serta Hasilnya BAGPRO PHTPR/IPM-SECP Sumatera Utara, Medan. Pertemuan Koordinasi Proyek PHT-PR dan Pemandu Lapang, LPP Yogyakarta, 31 juli-3. Agustus 2002. $12 \mathrm{p}$.

Mujiono dan Sabirin. 2002. Workshop Implementasi dan Program Pelatihan Pengendalian Hama Terpadu. Jakarta 20 . 22 . Igustus 2002 . $15 \mathrm{p}$.

Mumford, J.D. 1986. Control of The Cocoa Pod Borer (Atrocenops crame/la) : Progress a critical review. Dalam: Pushparajah, E., dan P.S. Chew (Eds.) Cocoa and Coconutts: Progress and outlook. Incorporated Soc. of Planters, Kuala Lumpur, Malaysia.. (Crop Protection Compedium 1999). C.AB International UK. p. 227-286 and S.H. Ho. 1988. Control of the cocoa pod borer (Conopomorpha cramella). (Crop Protection Compedium). C.AB
International Uk. Cocoa Growers Bullesin No. $40: 19-21$

Puslit Kopi dan Kakao. 1999. Uii Coba Lapangan Komponen Pengendalian Jasad Pengganggu Utama Unruk Mendukung PHT pada Perkebunan Kakao Rakyat. Badan Penelitian dan Pengembangan Pctanian, Pusat Penelitian Kopi dan Kakao. Jember. p. 98-119.

Untung, K. 2002. Paradigma baru PHT. Rapar koordinasi Konsultan PHT-PR/IPXISECP, Hotel Bumi Wiyata, Depok. 27-28 Maret 2002. $5 \mathrm{p}$.

Wardani, S. 2002. Peluang Pemasaran Kakao Indonesia. Workshop SL-PHT Kakao, Berau, Kalimatan Timur, 8 Nei 2002. 5 p.

Widiasih, R, 2004. Keanekaragaman Laba-Laba di Pertanaman Kakao dan Potensinya Mcmangsa Helopeltit sp. Skripsi. Fakultas Pertanian Unsoed, Purwokerto. $69 \mathrm{p}$. 